\title{
Selection, idioms, and the structure of nominal phrases with and without classifiers
}

\author{
Appendix A: Object-verb idioms in Korean
}

\section{Appendix A: Object-verb idioms in Korean}

This appendix and the next present the data from Korean and Vietnamese that we gathered. Each idiom is listed in a sentential context to illustrate its use, with the elements that are a fixed part of the idiom boldfaced. Any element that is not boldfaced can be changed.

\section{A1: N-V idioms, no functional elements}

We have found 65 idioms of this type, but do not believe this to be an exhaustive list.

\section{A1.1 Idioms that permit functional elements}

(1) il.il.kwu kwukup.cha-ka cho-lul tatwu-e talli-ko iss-ta. one.one.nine emergency.car-NOM second-ACC dispute-e run-KO exist-DECL

'The 119 ambulance is running in a very urgent situation.' (dispute a second = urgent)

(2) notongca-tul-uy pwulman-i hanul-ul ccilu-n-ta. worker-PL-GEN complaint-NOM sky-ACC pierce-PRES-DECL 'Workers complain a lot.' (pierce a sky = have a lot, great force)

(3) ku-nun somay-lul ket-ko saep-ey-man cennyemha-yess-ta. he-TOP sleeve-ACC roll.up-and business-in-only concentrate-PST-DECL

'He took a positive attitude and concentrated on his business.' (roll up sleeve $=$ take a positive attitude)

(4) wuli-nun siemeni-ey tayhayse yelsimhi hopak.ssi-lul kka-ss-ta. we-TOP mother.in.law-in about hard pumpkin.seed-ACC peel-PST-DECL

'We backbit our mother in law.' (peel pumpkin seeds = backbite) 
(5) wuli-nun icey kyewu katak-ul cap-ass-ta.

we-TOP now barely strand-ACC catch-PST-DECL

'We barely understood a situation by now.' (catch strand = get a clue)

(6) sihem-ey moltwuha-ki wihay chinkwu-tul-kwa pal-ul kkunh-kess-ta. test-in focus-NML in.order.to friend-PL-with leg-ACC cut.off-FUT-DECL

'I will discontinue a relationship with my friends to focus on my test.' (cut off a leg = discontinue a relationship)

(7) hyeng-i hayko-toy-ese sonkalak-ul ppal cikyeng-i-ta.

elder.brother-NOM fire-become-because finger-ACC suck condition-COP-DECL

'Because my elder brother was fired, he is in the situation of starving.' (suck finger $=$ starve)

(8) emma-ka atul-hantey son-ul ta tul-ess-ta.

mother-NOM son-DAT hand-ACC all hold.up-PST-DECL

'The mother gave up her son.' (hold up hand = give away/up)

(9) sokaything hwu Mina-ka na-hantey kaci-lul chi-ki-lo yaksokhay-ss-e.

blind.date after Mina-NOM I-DAT branch-ACC lop.off-NML-lo promise-PST-INT

'After the blind date, Mina promised me to set up a blind date for me.' (lop off branch = introduce to, make something subsidiary)

(10) ku-nun cho-lul chi-nun-tey senswu-i-ta.

he-TOP vinegar-ACC spread-ADN-NML player-COP-DECL

'He interrupts very well.' ( spread vinegar = interrupt)

sosel ssu-ci mal-ko ttokpalo malhay-la.

novel write-ci NEG.IMP-and straightforwardly tell-IMP

'Do not lie, and tell me straightforwardly.' (write novel = lie)

(12) kyengki-uy sung.phay-nun ttwukkeng-ul yel-e-pwaya al-ke-ya.

game-GEN victory.defeat-TOP lid-ACC open-e-try know-FUT-INT

'We will know the result of the victory or defeat of the game once the game is done.' (open lid = find out a result)

\section{A1.2 Idioms that permit non-functional elements}

ku nom-tul-i amwuli aklalhay-to wuli sayng.kacwuk-ul peski-ci-nun anh-ul that guy-PL-NOM however mean-although our alive.skin-ACC peel.off-ci-ADN NEG-ACC kes-i-ta.

NML-COP-DECL

'No matter how mean they are, they would not rob us of things we have.' (peel off skin $=$ rob of by employing all means) 
ipen-ey tayhak mwul-ul mek-ess-teni mollapokay this.time-in college water-ACC eat-PST-because unrecognizably selyen-toy-cye-ss-e. elegant-become-become-PST-INT

'Because she started her college this time, s/he became much more elegant.' (eat water = be influenced by surroundings)

nay-ka emma-uy sok-ul cengmal manhi kulk-ess-ta.

I-NOM mother-GEN stomach-ACC very much scratch-PST-DECL

'I made my mother worry very much.' (scratch stomach = make worry)

hyentay.in-tul-un ton-ttaymwuney mengey-lul ssu-ko sal-a-ka-n-ta.

modern.person-PL-TOP money-because yoke-ACC wear-ko live-a-go-PRES-DECL

'Modern people are heavily bound by money.' (wear a yoke = be bound by something)

yenkum mwuncey-uy khal-calwu-lul cwi-n salam-un palo

pension problem-GEN knife-hilt-ACC hold-ADN person-TOP exactly

kim-tayphyo-i-ta.

kim-representative-COP-DECL

'It is exactly the representative Kim who has an actual authority to the problem of pension system.' (hold a hilt of knife = have actual political power, authority)

celtaylo ku-nun i sasil-ey tayhayse nabal pwu-l salam-i ani-ta. absolutely he-TOP this fact-in about bugle blow-FUT person-NOM NEG-DECL

'Absolutely he is not a person who talks about it exaggeratedly.' (blow a bugle = talk about something absurdly, exaggeratedly)

choysen-ul taha-n ne-eykey tol-ul tenci-l salam-un amwuto eps-ul

best-ACC do-ADN you-DAT stone-ACC throw-ADN.FUT person-TOP anyone not.exist-ACC

kes-i-ta.

NML-COP-DECL

'There would not be anybody that criticizes you who did your best.' (throw a stone = criticize)

ku-ka yaksok-ul cikhi-tolok sswayki-lul pak-aya kyess-ta.

he-NOM promise-ACC keep-in.order.to wedge-ACC drive.in-indeed FUT-DECL

'We should take steps to make sure that he will keep his promise.' (drive in wedge = make certain)

ku il-i palmok-ul cap-ase yehayng-ul mos ka-yo.

that job-NOM ankle-ACC grab-because trip-ACC cannot go-POL

'The job prevented me from going to the trip.' (grab ankle = prevent, interrupt)

ku kyelceng-ey nongmin-tul-un wulpwun-uy phi-lul thohay-ss-ta.

that decision-in farmer-PL-TOP resentment-GEN blood-ACC vomit-PST-DECL

'For that decision, farmers were outraged.' (vomit blood = be outraged) 
(23) nay-ka chinhan chinkwu paltung-ul ccik-ess-ta.

I-NOM close friend instep-ACC hack-PST-DECL

'I betrayed my close friend.' (hack instep = betray)

(24) ipen il-ey kunye-tul-i chay-lul cap-ass-ta. this.time matter-in she-PL-NOM stick-ACC grab-PST-DECL

'The women lead on this matter.' (grab stick = lead)

han sitay-lul cwulum cap-ten ye.paywu-ka ecey kyothong sako-lo one period-ACC wrinkle grasp-used.to female.actress-NOM yesterday traffic accident-INST samanghay-ss-ta.

decease-PST-DECL

'The very famous female actress in this period deceased yesterday due to traffic accident.' (grasp wrinkle $=$ be famous)

(26) $\mathrm{ku}$ mal-un simcang-ul khok ccil-less-ta.

that word-TOP heart-ACC firmly stab-PST-DECL

'That word attacked me; that word gave some hurt to me.' (stab heart = attack an essential part)

(27) Kim Sanghyen eskheyi-eyse nalkay-lul phye-ta.

Kim Sanghyen SK-in wing-ACC spread-DECL

'Kim Sanghyen (the baseball player), his dream comes true in SK.' (spread wings = have one's dream come true)

(28) na-uy uykyen-i thulli-myen seng-ul ka-n-ta.

I-GEN opinion-NOM not.correct-if family.name-ACC change-PRES-DECL

'I swear that my opinion is correct.' (change family name = swear)

Aiphon-un nul nao-l ttaymata kakkwang-ul pat-nun-ta. iPhone-TOP always come.out-ADN whenever limelight-ACC receive-PRES-DECL

'IPhones always gain popularity whenever their new versions come out.' (receive limelight $=$ be popular)

(30) wuli hakkyo-uy ilum-ul kel-ko ku sang-ul kkok tha-keyss-ta. our school-GEN name-ACC hang.up-and that prize-ACC certainly win-FUT-DECL

'I will win the prize to be responsible for my school's reputation.' (hang up name = be responsible for one's reputation)

seymwu kemsa-lo ku hoysa-nun khukey seli-lul mac-ass-ta.

tax inspection-because that company-TOP greatly frost-ACC get.hit-PST-DECL

'Due to the tax inspection, the company had a great loss.' (get hit by frost = gain damage or loss)

(32) ku-nun pwumo-nim maum-ey mos-ul pak-ass-ta.

he-TOP parent-HON heart-DAT nail-DECL drive-PST-DECL

'He hurt his parents.' (drive nail = hurt) 
(33) kutul-un sikminci thongchi-ey makak-ul tulenay-ess-ta. they-TOP colony reign-in horse.leg-ACC bring.out-PST-DECL

'They disclosed the hidden details of their colonization.' (bring out a horse leg $=$ disclose hidden details)

(34) tasi nasa-lul kkawk coi-ko yelsimhi saynghwal-ha-kess-ta.

again screw-ACC firmly tighten-and hard life-do-FUT-DECL

'I will control my mind and live a life in full.' (tighten screw = control)

(35) Chelswu-nun mekmwul-ul kkwayna mek-ess-ta.

Chelswu-TOP ink-ACC sufficiently eat-PST-DECL

'Chelswu has been educated to some sufficient extent.' (eat ink = be educated)

(36) nayil-pwuthe-nun sangsa palpatak-ul halth-ci anh-kess-ta.

tomorrow-from-TOP boss sole-ACC lick-ci NEG-FUT-DECL

'I will not flatter my boss from tomorrow.' (lick sole $=$ flatter)

(37) ye.haksayng-tul-un ku iyaki-ey cangtan-ul cal macchwu-ess-ta.

female.student-PL-TOP that story-in rhythm-ACC well set-PST-DECL

'The female students listened to the story carefully and agreed with it.' (set rhythm $=$ listen carefully and agree)

(38) na-nun chel.phan-ul kkal-ko ku namca-eykey kopaykha-yess-ta.

I-TOP iron.pad-ACC spread.out-and that guy-DAT propose-PST-DECL

'I was brash, and proposed to the guy.' (spread out iron pad = be brash)

\section{A1.3 Idioms that permit both}

pwuceng kongcikca-uy ssi-lul malli-kess-ta.

corruption official-GEN seed-ACC dry-FUT-DECL

'We will get rid of the officials' corruptions.' (dry seeds = get rid of)

ce nom-tul-i ta santhong-ul

kkay-ss-ta.

that guy-PL-NOM all container.for.branches-ACC break-PST-DECL

'Those guys ruined the matter.' (break a container for branches $=$ ruin)

kipwu yeksa-ey hoyk-ul ku-u-si-n Kwon sacang-nim.

donation history-in stroke-ACC draw-u-HON-ADN Kwon boss-HON

'Boss Kwon who has made a great contribution to the history of donation' (draw a stroke = make a crucial contribution)

ne cengmal khong.pap mek-eya cengsin-ul chali-keyss-ni?

you really bean.rice eat-have.to mind-ACC recover-FUT-Q

'Are you going to wake up if you have to go a jail?' (eat bean rice = go to a jail) 
wuli-nun kan-ul coli-ko iss-ess-ta.

we-TOP liver-ACC boil.down-KO exist-PST-DECL

'We were being very nervous.' (boil down liver = be nervous)

(44) kamthwu-lul sse-ss-u-myen ku-ey kelmac-nun phwumkyek-ul kacy-eya ha-n-ta.

hat-ACC put.on-PST-u-if that-in befit-ADN dignity-ACC own-should do-PRES-DECL

'If you are in a position of authority, you should have a dignity befitting that .' (put on a traditional hat $=$ gain authority)

(45) ku cong-un temtheki-lul ssu-ko cwukim-ul tangha-yess-ta.

that servant-TOP worry-ACC wear-and killed-ACC suffer-PST-DECL

'That servant got all the blame, and was killed.' (wear worry = get blamed)

\section{A1.4 Idioms that are fixed}

wunun aki-lul tallaynu-lako ttam-ul ppay-ss-ta.

crying baby-ACC soothe-because sweat-ACC wring.out-PST-DECL

'I had a hard time because I soothed the crying baby.' (wring out sweat = have a hard time)

$$
\text { kahayca-nun casin-i ohilye phihayca-i-n chek kephwum-ul mwul-ko }
$$

assailant-TOP self-NOM rather victim-COP-ADN pretending foam-ACC bite-and

taytul-ess-ta.

defy-PST-DECL

'The assailant pretended to be rather a victim, and was very enraged and defied.' (bite a foam = be enraged)

$$
\begin{aligned}
& \text { moin salam-tul-i motwu hye-lul naytwul-ess-ta. } \\
& \text { gathered person-PL-NOM all tongue-ACC wave-PST-DECL }
\end{aligned}
$$

'All gathered people were very astonished.' (wave a tongue = get astonished)

naynyen-ey-to heli.tti-lul coll-a-may-ko cal sal-a-po-ca.

next.year-in-too waist.belt-ACC tight-and-tie-and well live-a-try-EXHORT

'Let's be frugal and live well next year, too.' (tighten one's belt = frugal)

onul sihem-eyse cwuk-ul sse-ss-ta.

today test-in portridge-ACC cook-PST-DECL

'I failed in the test today.' ( cook a portridge $=$ fail)
ku-uy cenkwa-ka
kongkay-toy-ca
kakkawun chinkwu-tul-to
he-GEN crimnal.record-NOM publicize-become-once close friend-PL-even

sayk.ankyeng-ul kki-ess-ta.

color.glasses-ACC wear-PST-DECL

'Once his criminal record became publicized, even his close friends got to have bad opinions about him.' (put on color glasses $=$ have bad opinions or prejudices) 
soyoung-un macimak-kkaci sichimi-lul ttey-ss-ta.

soyoung-TOP last-till name.tag-ACC detach-PST-DECL

'Soyoung pretended not to know about it till the end.' (detach a name tag = pretend not to know)

uysa cinchal hwu-ey twutie saci-lul phye-ss-ta.

doctor examination after-in finally limbs-ACC unfold-PST-DECL

'After the doctor's examination, finally I got comfortable without any worries.' (unfold limbs = get comfortable with no worries)

(54) na ce kapang cem ccik-ess-e.

I that bag dot mark-PST-INT

'I kept one eye on the bag.' (mark a dot = keep one eye on)

nay-ka swutkalak-ul noh-ki cen-kkaci-nun helakha-ci mos-ha-n-ta.

I-NOM spoon-ACC put.down-NML before-until-TOP permit-ci NEG-do-PRES-DECL

'Until I die, I will not permit it.' (put down a spoon = die)

(56) sengkongha-myen na-hantey saykki chye-la.

succeed-if I-DAT baby bear-IMP

'If you succeed (in your blind date), you should introduce me (to a girl).' (baby bear = introduce to)

(57) wuli-nun ip-ul mo-ase Hana-lul chingchanha-yess-ta.

we-TOP lip-ACC collect-and Hana-ACC praise-PST-DECL

'We praised Hana all together (without any disagreement).' (collect lips = act unanimously)

Chelswu-ka ipen sihem-eyse miyek.kwuk-ul mek-ess-ta.

Chelswu-NOM this test-in seaweed.soup-ACC eat-PST-DECL

'Chelswu failed this test.' (eat seaweed soup = fail)

Kyengswu-nun sihem-i takao-myen hangsang nal-ul seywu-n-ta.

Kyengswu-TOP test-NOM approach-if always blade-ACC stand-PRES-DECL

'Kyengswu becomes always sensitive and nervous whenever the test date approaches.' (stand blade $=$ be sensitive)

(60) celmun yeseng-tul-i chongtay-lul mey-ess-ta.

young woman-PL-NOM gun.stock-ACC carry-PST-DECL

'Young women were the representative of the work, and led it.' (carry gun stock = become a representative and lead)

(61) Hana-ka ttum-ul olaystongan tuli-ess-ta.

Hana-NOM steam-ACC for.a.while let.in-PST-DECL

'Hana took an interval of time before she told about something.' (let the rice settle in its own steam $=$ give an interval of time) 
(62) sensayngnim-i yel-ul manhi pat-u-si-ess-ta.

teacher-NOM heat-ACC much receive-u-HON-PST-DECL

'The teacher got very angry.' (receive heat = get angry)

(63) Jwumi-nun motun chongkak-hantey kkoli-lul chy-ess-ta.

Jwumi-TOP all unmarried.man-DAT tail-ACC wag-PST-DECL

'Jwumi flirted with all the guys.' (wag tail = flirt)

(64) Khulisu-nun ecey sicang-eyse pakaci-lul sse-ss-ta.

Chris-TOP yesterday market-in bowl-ACC wear-PST-DECL

'Chris was ripped off in the market yesterday.' (wear bowl = be rip off)

$\mathrm{ku}$ cali-nun nay-ka myengham-ul naymil manhan kos-i ani-ta.

that position-TOP I-NOM name.card-ACC hold.out worth place-NOM NEG-DECL

'The position is not the place that I can show my identification (i.e., there are many other people who are more excellent than me. I am not much as competitive as they are).' (hold out name card = identify oneself)

\section{A2: N-V Idioms with functional elements}

All of these permit the functional elements to vary.

(1) kwansim-kwa yelceng-ulo han wumwul-ul pha-la. interest-and passion-with one well-ACC dig-IMP

'Focus on one matter with your interest and passion.' (dig one well $=$ focus on one matter) wuli-nun onul-pwuthe han soth.pap-ul mek-nun-ta. we-TOP today-from one cauldron.rice-ACC eat-PRES-DECL

'From today we live in the same house.' (eat one cauldron rice = live in the same house; work together in the same team)

(3) swuswul-i sengkongcekulo kkuthna-se icey han swum-ul tolli-n-ta. surgery-NOM successfully finish-because now one breath-ACC turn-PRES-DECL

'Because the surgery was successfully finished, now we get relieved.' (turn one breath = get relieved)

(4) wuli-nun han ipwul-ul teph-nun sai-ya.

we-TOP one blanket-ACC cover-ADN relation-INT

'We are married.' (cover one blanket = marry)

ne-nun sinsa-losse ettehkey twu mal-ul ha-ni?

you-TOP gentle.man-as how two word-ACC do-Q

'How come do you as a gentleman change your mind so easily?' (say two words = change one's mind so easily) 
(6) Chelswu-nun yang tali-lul kelci-n-ta.

Chelswu-TOP both leg-ACC span-PRES-DECL

'Chelswu is a two-timer.' ( span two legs $=$ date more than one person at a time)

(7) i kos-ey cip-ul sa-myen ancen-ha-ko kyengchi-to coha-se twu swu-lul this place-in house-ACC purchase-if safety-do-and landscape-too good-because two move-ACC po-nun kes-i-ta. see-ADN thing-COP-DECL

'If you purchase a house in this place, you gain double profits because it is safe and its landscape is great.' (see two moves = gain double profits)

(8) wuli-ka icey han pay-lul tha-ss-ta. we-NOM now one boat-ACC ride-PST-DECL

'We now share a destiny.' (ride one boat = share the same destiny)

(9) Kim sacang sosik-ey wuli motwu han pang-ul mek-ess-ta. Kim boss news-in we all one fist-ACC eat-PST-DECL

'We were very shocked at the news about the boss Kim.' (eat one fist $=$ be shocked)

ku-nun sakwa-nun khenyeng han swul-ul te tte-se hwa-lul nay-ess-ta. he-TOP apology-TOP rather.than one spoon-ACC more scoop-and angry-ACC make-PST-DECL 'He made the situation more worse by getting angry rather than apologizing.' (scoop one spoon more $=$ make the situation worse; outwit)

(11) Kim sacang-i han ken-ul olly-ess-ta.

Kim boss-NOM one matter-ACC raise-PST-DECL

'Our boss Mr. Kim made some achievements.' (raise one matter = make some achievements)

(12) Min kyoswu-ka haksayng-tul-eykey han thek-ul sso-ass-ta.

Min professor-NOM student-PL-DAT one tray-ACC shoot-PST-DECL

'Professor Min treated his students.' (shoot one tray = treat)

(13) han nwun-ul phal-ci mal-ko kongpwu-man hay-la.

one eye-ACC sell-ci NEG-and study-only do-IMP

'Focus on studying.' (sell one eye $=$ not to focus)

(14) Hana-nun mikwuk-eyse twu mali thokki-lul motwu cap-ass-ta.

Hana-TOP America-in two CL rabbit-ACC all catch-PST-DECL

'Hana accomplished what she has planned in America.' (catch two rabbits = accomplish) 